Review Article

\title{
Using Cell-Based Strategies to Break the Link between Bronchopulmonary Dysplasia and the Development of Chronic Lung Disease in Later Life
}

\author{
Megan O'Reilly ${ }^{1}$ and Bernard Thébaud ${ }^{2,3}$ \\ ${ }^{1}$ Department of Pediatrics, Women and Children's Health Research Institute, Katz Group Centre for Pharmacy and Health Research, \\ University of Alberta, Edmonton, AB, Canada T6G 2E1 \\ ${ }^{2}$ Sprott Centre for Stem Cell Research, Ottawa Hospital Research Institute, 501 Smyth Road, Ottawa, ON, Canada K1H 8L6 \\ ${ }^{3}$ Division of Neonatology, Department of Pediatrics, Children's Hospital of Eastern Ontario (CHEO) and CHEO Research Institute, \\ 401 Smyth Road, Ottawa, ON, Canada K1H 5B2
}

Correspondence should be addressed to Bernard Thébaud; bthebaud@ohri.ca

Received 7 September 2012; Accepted 16 December 2012

Academic Editor: Leif Bjermer

Copyright (C) 2013 M. O’Reilly and B. Thébaud. This is an open access article distributed under the Creative Commons Attribution License, which permits unrestricted use, distribution, and reproduction in any medium, provided the original work is properly cited.

\begin{abstract}
Bronchopulmonary dysplasia (BPD) is the chronic lung disease of prematurity that affects very preterm infants. Although advances in perinatal care have changed the course of lung injury and enabled the survival of infants born as early as 23-24 weeks of gestation, BPD still remains a common complication of extreme prematurity, and there is no specific treatment for it . Furthermore, children, adolescents, and adults who were born very preterm and developed BPD have an increased risk of persistent lung dysfunction, including early-onset emphysema. Therefore, it is possible that early-life pulmonary insults, such as extreme prematurity and BPD, may increase the risk of COPD later in life, especially if exposed to secondary challenges such as respiratory infections and/or smoking. Recent advances in our understanding of stem/progenitor cells and their potential to repair damaged organs offer the possibility of cell-based treatments for neonatal and adult lung injuries. This paper summarizes the long-term pulmonary outcomes of preterm birth and BPD and discusses the recent advances of cell-based therapies for lung diseases, with a particular focus on BPD and COPD.
\end{abstract}

\section{Introduction}

Intrauterine and early postnatal environments have been shown to play an influential role in the development and maturation of the lung [1]. Suboptimal conditions that interfere with normal development may result in altered lung structure and function and increase the risk for disease later in life. Alarmingly, the onset of adult lung disease following inadequate development and maturation is becoming apparent at an early age. Recently, Wong and colleagues [2] showed that survivors of moderate-severe bronchopulmonary dysplasia (BPD) presented with emphysema in early adulthood (17-33 years of age). Understanding how the fetus and developing lung responds to intrauterine alterations and adapts to the postnatal environment can teach us about basic biology and the implications for adult lung diseases $[3,4]$.

\section{Early Life Origins of BPD}

Development of the lung throughout gestation is a vital process required for adequate fetal to neonatal transition at birth. As the fetal lung proceeds through its developmental stages in utero, it becomes progressively prepared for exposure to the external environment. Successful transition to ex utero life at birth is dependent upon the ability of the lungs to effectively function as an organ of gas exchange. Indeed, organs of the developing fetus and newborn infant are extremely plastic and are particularly vulnerable to intrauterine and early postnatal environments. Therefore, being born preterm with structurally immature and surfactant-deficient lungs usually results in exposure to many environmental factors that can impact later lung development and function. It is likely that the long-term pulmonary outcomes of preterm birth 
and BPD are a result of complex programming mechanisms influenced by both environmental and epigenetic changes that take place during the period of development $[1,5]$. Many fetal and postnatal factors associated with preterm birth modulate the pathogenesis of $\mathrm{BPD}$, including severity or prematurity, oxidative stress from supplemental oxygen therapy, ventilator-induced lung injury, fetal and/or postnatal infection or inflammation, and nutrition [6, 7]; therefore, identification of the injurious factors contributing to the development of BPD is often hampered by its multifactorial etiology.

\section{Preterm Birth and BPD}

Over the past few decades, advances in perinatal care have improved the outcome for infants born extremely preterm (i.e., between 24 and 28 weeks of gestation), and there is currently a rising trend in the rate of survival. However, with the shift in the limit of viability toward a lower gestational age, the task of protecting the more immature lung from injury becomes increasingly challenging. Severity of prematurity is one of the major risk factors for the development BPD [8]. Due to their immature pulmonary surfactant system, immature alveoli, and underdeveloped surface area for adequate gas exchange, almost all extremely preterm infants require prolonged respiratory support to ensure survival [6]; however, this further increases their risk of developing BPD. Furthermore, infants who were born extremely preterm have a high incidence of rehospitalization during their first year of life (over $40 \%$ of prematurely born infants), with the most common cause for re-hospitalization being respiratory infection [9]. It has been demonstrated by many studies that prematurely born infants who develop BPD carry a life-long risk of poor pulmonary health; this is discussed in detail later.

\section{Short- and Long-Term Pulmonary Outcomes of Preterm Birth and BPD}

Recent evidence suggests that BPD has long-term respiratory complications that reach beyond childhood into adulthood. Numerous follow-up studies show an increased risk of impaired lung function in infancy, childhood, adolescence, and early adulthood. Few studies have investigated the longterm pulmonary outcome in adults exceeding their early 20 's. This is particularly important because it is only now that large populations of very preterm subjects are reaching middleage adulthood (i.e., 35-45 years of age) and may be at risk of persistent respiratory morbidity.

4.1. Pulmonary Outcomes during Infancy. Several studies have documented abnormal pulmonary function during infancy (up to approximately 2 years of age) following preterm birth and development of BPD [10-15]. These studies indicate that prematurely born infants (both with and without BPD) experience reduced lung function in the first few months of life. Compared to term-born infants, preterm infants with BPD are more likely to be symptomatic with recurrent wheezing [14] and require re-hospitalization during the first 2 years of life due to acute respiratory distress and respiratory tract illness $[13,15]$. Functional tests show significantly decreased airway function in prematurely born infants compared to term born controls, including decreased forced expiratory volume in 0.5 seconds $\left(\mathrm{FEV}_{0.5}\right)[12,14]$, reduced forced expiratory flow rates $\left(\mathrm{FEF}_{50 \%}, \mathrm{FEF}_{75 \%}\right.$, and $\left.\mathrm{FEF}_{25-75 \%}\right)[10,12,14]$, reduced functional residual capacity (FRC) [11, 15], and increased lung residual volume (RV) [14]. Reduced pulmonary diffusing capacity has also been demonstrated in clinically stable infants and toddlers with chronic lung disease of prematurity, suggesting impairment of alveolar development, albeit alveolar volume appeared normal [16]. Furthermore, respiration variables of prematurely born infants have been shown to be significantly altered during the first 2 years of life, indicated by a faster breathing frequency $[11,15]$, greater tidal volume $\left(V_{T}\right)[11]$, increased amount of dead space [11], and greater minute ventilation $\left(V_{E}\right)$ [11]. There are also considerable differences in compliance and resistance of the respiratory system, with preterm infants presenting with lower compliance and higher resistance compared to term-born controls [11].

4.2. Pulmonary Outcomes during Childhood. There is a wealth of information regarding pulmonary outcomes during childhood following preterm birth, with the majority of follow-up studies assessing respiratory symptoms, pulmonary function, and exercise capacity in school-age children (approximately 7 to 12 years of age) [17]. Indeed, many studies indicate that prematurely born children have an increased risk of respiratory symptoms, including cough [13, $18]$, wheeze $[13,18]$, and asthma $[18,19]$. Assessment of pulmonary function throughout childhood shows that preterm birth increases the risk of impaired lung function, with studies showing significantly impaired respiratory function variables in prematurely born children compared to termborn controls; these impairments are particularly common in individuals who develop BPD following preterm birth. Poor respiratory function variables include decreased $\mathrm{FEV}_{1}$ [1929], reduced $\mathrm{FEF}_{25 \%-75 \%}[19-24,26,27,29,30]$, reduced FVC [19-24, 26, 29], decreased total lung capacity (TLC) [19, 21], and increased RV $[13,19,21,22,28]$, all of which indicate varying degrees of airflow obstruction, as well as decreased diffusing capacity of the lungs [27, 28]. Furthermore, exercise capacity is compromised in ex-preterm children (both with and without BPD) compared to term-born control subjects. In response to maximal exercise tests, exercise performances of prematurely born children were indicative of reduced aerobic power, as shown by a significantly lower maximal heart rate [13, 25], faster breathing frequency [22, 24], smaller $V_{T}$ [22], reduced maximal oxygen consumption $\left(V \mathrm{O}_{2 \max }\right)$ $[21-23,25]$, reduced maximal minute ventilation $\left(V_{E \max }\right)$ [23], and shorter exercise time [23] and distance [21, 25]; these functional differences are consistent with long-term alterations in cardiopulmonary development. Interestingly, oxygen supplementation during the neonatal period in very low birth weight infants has been identified as an independent risk factor for asthma in childhood [31].

Some of the childhood studies described earlier were conducted in children who were born in the presurfactant and 
TABLE 1: Studies examining the therapeutic effect of stem/progenitor cells in experimental models of neonatal chronic lung disease.

\begin{tabular}{|c|c|c|c|c|}
\hline Experimental model & $\begin{array}{l}\text { Therapeutic cell or } \\
\text { product }\end{array}$ & Outcomes & Suggested mechanism & References \\
\hline \multirow{8}{*}{$\begin{array}{l}\text { Hyperoxia-induced } \\
\text { neonatal lung injury }\end{array}$} & $\begin{array}{l}\text { Bone marrow-derived } \\
\text { MSCs (i.t.) }\end{array}$ & $\begin{array}{l}\text { Improved survival } \\
\text { Improved alveolar structure/prevented } \\
\text { alveolar arrest } \\
\text { Prevented vascular growth arrest } \\
\text { Improved exercise capacity } \\
\text { Reduced pulmonary hypertension }\end{array}$ & $\begin{array}{l}\text { Engraftment as AT2 } \\
\text { Paracrine mechanisms }\end{array}$ & {$[48]$} \\
\hline & $\begin{array}{l}\text { Bone marrow-derived } \\
\text { MSCs or CdM (i.v.) }\end{array}$ & $\begin{array}{l}\text { Improved alveolar structure/prevented } \\
\text { alveolar arrest } \\
\text { Attenuated inflammation } \\
\text { Prevented vascular growth arrest } \\
\text { Prevented pulmonary hypertension }\end{array}$ & $\begin{array}{l}\text { Paracrine mechanisms } \\
\text { Immunomodulatory effects }\end{array}$ & {$[54]$} \\
\hline & $\begin{array}{l}\text { Bone marrow-derived } \\
\text { MSCs or CdM (i.v.) }\end{array}$ & $\begin{array}{l}\text { Increased number of BASCs } \\
\text { Improved alveolar structure/prevented } \\
\text { alveolar arrest }\end{array}$ & $\begin{array}{l}\text { Stimulation of BASCs } \\
\text { Paracrine mechanisms }\end{array}$ & {$[55]$} \\
\hline & $\begin{array}{l}\text { Bone marrow-derived } \\
\text { MSCs (i.p.) }\end{array}$ & $\begin{array}{l}\text { Improved survival } \\
\text { Improved alveolar structure/prevented } \\
\text { alveolar arrest } \\
\text { Attenuated inflammation } \\
\text { Inhibited lung fibrosis }\end{array}$ & $\begin{array}{l}\text { Engraftment as AT2 } \\
\text { Reduction in ECM } \\
\text { remodeling and fibrosis gene } \\
\text { expression (TGF- } \beta 1 \text {, collagen } \\
1 \alpha \text {, TIMP-1) } \\
\text { Anti-inflammatory effects }\end{array}$ & {$[56]$} \\
\hline & $\begin{array}{l}\text { Bone marrow-derived } \\
\text { MSC-CdM (i.v.) }\end{array}$ & $\begin{array}{l}\text { Improved alveolar structure } \\
\text { Attenuated myofibroblast infiltration } \\
\text { Improved lung function } \\
\text { Reversed pulmonary hypertention and } \\
\text { RV hypertrophy } \\
\text { Attenuated pulmonary arterial } \\
\text { remodeling } \\
\text { Rescued loss of pulmonary blood vessels }\end{array}$ & $\begin{array}{l}\text { Paracrine mechanisms } \\
\text { Cytoprotective effects } \\
\text { Activation of BASCs }\end{array}$ & {$[57]$} \\
\hline & $\begin{array}{l}\text { hUCB-derived MSCs } \\
\text { (i.t.) }\end{array}$ & $\begin{array}{l}\text { Improved survival and growth restriction } \\
\text { Improved alveolar structure } \\
\text { Attenuated lung fibrosis, inflammation, } \\
\text { and ROS activity }\end{array}$ & $\begin{array}{l}\text { Paracrine anti-inflammatory, } \\
\text { antifibrotic and antioxidative } \\
\text { effects }\end{array}$ & {$[59,60]$} \\
\hline & $\begin{array}{l}\text { hUCB-derived MSCs } \\
\text { and MSC-CdM (i.t.) } \\
\text { Umbilical } \\
\text { cord-derived PCs and } \\
\text { PC-CdM (i.t.) }\end{array}$ & $\begin{array}{l}\text { Prevented and restored impaired alveolar } \\
\text { growth } \\
\text { Improved lung function and exercise } \\
\text { capacity } \\
\text { Prevented impaired lung angiogenesis } \\
\text { Prevented pulmonary arterial wall } \\
\text { remodeling and RV hypertrophy } \\
\text { Persistent benefit on lung architecture } \\
\text { and exercise capacity at } 6 \text { months } \\
\text { No adverse effects on lung structure in } \\
\text { treated control animals at } 6 \text { months }\end{array}$ & Paracrine mechanisms & {$[58]$} \\
\hline & BMDACs (i.v.) & $\begin{array}{l}\text { Improved alveolar structure } \\
\text { Improved vascular growth }\end{array}$ & Paracrine mechanisms & {$[72]$} \\
\hline $\begin{array}{l}\text { LPS-induced (i.a.) } \\
\text { neonatal lung injury }\end{array}$ & hAECs (i.t.; i.v.) & $\begin{array}{l}\text { Improved alveolar structure } \\
\text { Increased surfactant protein expression } \\
\text { Attenuated inflammation }\end{array}$ & Immunomodulatory effects & {$[73]$} \\
\hline
\end{tabular}

Acronyms: AT2: alveolar epithelial type 2; BASC: bronchioalveolar stem cell; BMDAC: bone marrow-derived angiogenic cell; CdM: conditioned media; ECM: extracellular matrix; hAEC: human amnion epithelial cell; hUCB: human umbilical cord blood; i.a.: intraamniotic; i.p.: intraperitoneal; i.t.: intratracheal; i.v.: intravenous; LPS: lipopolysaccharide; MSC: mesenchymal stem cell; PC: perivascular cell; ROS: reactive oxygen species; RV: right ventricle; TGF- $\beta 1$ : transforming growth factor- $\beta 1$; TIMP1: tissue inhibitor of metalloproteinase 1 . 
TABLE 2: Studies examining the therapeutic effect of stem/progenitor cells in experimental models of adult chronic lung disease.

\begin{tabular}{llll}
\hline Experimental model & Therapeutic cell or product & Outcomes & Suggested mechanism \\
\hline $\begin{array}{l}\text { Cigarette smoke-induced } \\
\text { adult lung injury }\end{array}$ & $\begin{array}{l}\text { Bone marrow-derived } \\
\text { MSCs, CdM, and BMCs } \\
\text { (i.v.) }\end{array}$ & $\begin{array}{l}\text { Restoration of alveolar structure } \\
\text { Increased pulmonary vascularity } \\
\text { Alleviation of pulmonary } \\
\text { hypertension (by BMCs) }\end{array}$ & $\begin{array}{l}\text { Paracrine mechanisms } \\
\text { Recruitment of BMCs by } \\
\text { donor cells }\end{array}$ \\
\hline $\begin{array}{l}\text { Papain-induced adult } \\
\text { lung injury }\end{array}$ & $\begin{array}{l}\text { Bone marrow-derived } \\
\text { MSCs (i.v.) }\end{array}$ & Improved alveolar structure & $\begin{array}{l}\text { Engraftment and AT2 } \\
\text { differentiation } \\
\text { Reduced alveolar epithelial } \\
\text { apoptosis }\end{array}$ \\
\hline
\end{tabular}

Adipose tissue-derived MSCs (i.v. or cultured on PGA and transplanted after LVRS)

Elastase-induced (i.t.) adult lung injury MSCs (i.t.)
Restored gas exchange Improved exercise tolerance

Growth factor release (HGF, VEGF)

Preservation of alveolar structure Reduced inflammation Upregulated growth factors

Lung resident multilineage progenitors $\mathrm{Sca}^{+} \mathrm{CD} 45^{-} \mathrm{CD} 31^{-}$ (i.t.)

Human ESC-derived cells with AT2 epithelial phenotype (i.t.)

Bleomycin-induced adult lung injury (i.t.)

Bone marrow-derived MSCs (i.v.)

hUC Wharton's jelly-derived MSCs (i.v.)

Bone marrow-derived $\mathrm{HSCs} \pm \mathrm{KGF}$ overexpression (i.v.)

Bleomycin-induced adult lung injury (i.n.)
hAECs (i.p.; i.v.)
Improved survival

Attenuated alveolar damage

Improved body weight and

survival

Improved arterial oxygen

saturation

Decreased collagen deposition

Reduced fibrosis and inflammation

Reduced fibrosis

Reduced fibrosis

Reduced fibrosis and collagen

deposition

Improved lung function

Modulated inflammatory

response
Paracrine mechanisms

HGF, EGF, and secretory

leukocyte protease inhibitor

[65]

secretion

Immunomodulatory effects

Paracrine mechanisms

[76]

Engraftment and AT1

differentiation

Paracrine mechanisms

IL-1 receptor antagonism

Decrease in NO metabolites, proinflammatory, and angiogenic cytokines

$[66,68,70]$

Decreased TGF- $\beta$ and TIMP activity

Increased MMP-2 activity

KGF-induced endogenous

AT2 cell proliferation

Acronyms: AT1: alveolar epithelial type 1; AT2: alveolar epithelial type 2; BMC: bone marrow-derived cells; CdM: conditioned media; EGF: epidermal growth factor; EPC: endothelial progenitor cell; HGF: hepatocyte growth factor; HSC: hematopoietic stem cell; hAEC: human amnion epithelial cell; hUC: human umbilical cord; IL: interleukin; i.n.: intranasal; i.p.: intraperitoneal; i.t.: intratracheal; i.v.: intravenous; KGF: keratinocyte growth factor; LVRS: lung volume reduction surgery; MMP-2: matrix metalloproteinase 2; MSC: mesenchymal stem cell; NO: nitric oxide; PGA: polyglycolic acid; TGF- $\beta$ : transforming growth factor- $\beta$; TIMP: tissue inhibitor of metalloproteinase; VEGF: vascular endothelial growth factor.

preantenatal steroid era $[13,23,30]$. However, the remaining studies discussed earlier were performed in the postsurfactant and postantenatal steroid era, which indicates that even with the introduction of pre and postnatal interventions to reduce the severity of $\mathrm{BPD}$, poor pulmonary outcomes are still evident in childhood, perhaps as a consequence of earlier interference with normal lung development.

4.3. Pulmonary Outcomes during Adolescence and Young Adulthood. Poor pulmonary outcomes observed in prematurely born children throughout childhood remain prevalent into adolescence and young adulthood [17]. In comparison to the numerous extensive studies performed in ex-preterm children, there are few studies that have investigated expreterm adults older than 20 years. Recent studies of adolescents and adults have assessed pulmonary outcomes from approximately 14 to 22 years of age [32-35]. Respiratory symptoms still persist to late adolescence and early adulthood, with significantly more ex-preterm subjects reporting the occurrence of cough, wheeze, and asthma compared to term-born controls [32-34]. Prematurely born adolescents also had a significantly greater risk of being hospitalized 
for respiratory problems [32]. As with pulmonary function outcomes in childhood, $\mathrm{FEV}_{1}, \mathrm{FEF}_{25 \%-75 \%}$, and $\mathrm{FVC}$ all remained significantly lower in late adolescence and young adulthood following preterm birth compared to control subjects $[25,29,35,36]$. Additionally, exercise capacity remained lower than that of controls, with subjects exhibiting significantly lower maximal heart rate, faster breathing frequency, reduced $V \mathrm{O}_{2 \max }$, reduced $V_{E \max }$, and shorter exercise distance in response to exercise tests [25, 35]. Of particular interest is the recent evidence showing higher exhaled breath condensate 8-isoprostane levels in ex-preterm nonBPD and BPD adolescents, indicative of significantly increased oxidative stress in their airways; this suggests the presence of an ongoing airway disease [36]. More alarmingly, studies are surfacing of impaired alveolar development and emphysema at adult age in former preterm infants with BPD $[2,37]$. Data from such follow-up studies suggest that very preterm birth, or associated factors, can permanently affect the small conducting airways and gas exchanging region and may contribute to impaired lung function observed further into adulthood.

It is important to note that the adolescent and young adulthood studies described earlier were undertaken with individuals born during the presurfactant era (birth years of the subjects ranged from 1977 to 1985 ), with the exception of the studies by Kotecha et al., 2012 [29], and Filippone et al., 2012 [36]. Although similar pulmonary outcomes are still observed in the postsurfactant era during childhood, further longitudinal follow-up studies are required from the present survivors of preterm birth who were treated with surfactant to gain a thorough understanding of the long-term pulmonary outcomes. To date, there are limited functional studies that have been undertaken in adolescent and young adult subjects from the postsurfactant era (i.e., infants born after 1990). It is anticipated that in the forthcoming years, further data will become available, since preterm individuals that were the first to be treated with synthetic surfactant are now entering this age range.

\section{Neonatal Lung Injury and the Influence of Aging on Lung Structure and Function}

It is well known that aging is associated with progressive decline in lung function, a result of many age-induced structural alterations to the lung $[38,39]$. Increases in the total alveolar airspace volume with enlargement of the alveolar ducts are common consequences of aging and are thought to arise from increases in the size and frequency of interalveolar pores [40]. A reduction in the supporting parenchymal tissue within the lung can result in collapse of the small conducting airways during normal breathing, especially during expiration, potentially causing gas trapping and hyperinflation, more commonly known as "senile emphysema." The increase in airspace size resulting from loss of supporting tissue and a decrease in elastic recoil are likely the cause of reported increases in lung compliance with aging [38, 39, 41]. Furthermore, aging is thought to be associated with a decline in pulmonary immune function [40], and increases in the number of immune cells in bronchoalveolar lavage fluid have been reported in the aging human population [42]. This evidence of persistent low-grade inflammation in the respiratory tract is thought to cause oxidant-mediated injury to the lung matrix, resulting in a loss of alveoli and impaired gas exchange [42].

The recent reports of increased oxidative stress in the airways of ex-preterm nonBPD and BPD adolescents [36] in conjunction with reports of early-onset emphysema in expreterm BPD adults $[2,37]$ suggest that preterm birth and the subsequent development of BPD may accelerate and/or exacerbate the normal age-induced pulmonary changes. Therefore, it is reasonable to consider that early life pulmonary insults, such as preterm birth per se and BPD, may increase the risk of chronic obstructive pulmonary disease (COPD) later in life [43], especially if the lungs of ex-preterm BPD adults are exposed to secondary challenges such as respiratory infections and/or smoking.

Progress toward decreasing the incidence/severity of BPD over the next few years using currently available techniques and strategies is likely (i.e., optimization of antenatal management combined with surfactant and early noninvasive ventilatory support targeting lower oxygen saturations) [44]. However, currently, there is a lack of treatment for both BPD and the chronic lung disease that consequently ensues later in life. Therefore, a further understanding of the mechanisms involved in lung development, injury, and repair are necessary in order to advance toward preventing lung injury and/or promoting lung development/regeneration in extremely and very prematurely born infants. Exciting discoveries in stem cell biology over recent years may offer new insight into the pathogenesis of BPD and, more importantly, open new therapeutic avenues. Consequently, as we advance in the quest to provide therapeutic stem/progenitor cell-based strategies for the prevention and repair of neonatal lung injury, our focus may need to extend to potential therapies for the ex-preterm BPD adult lung exhibiting early-onset emphysema/COPD. Indeed, $\mathrm{BPD}$ and $\mathrm{COPD}$ exhibit common therapeutic targets [3].

\section{Therapeutic Potential of Stem/Progenitor Cells for Lung Repair/Regeneration}

Recent animal and human studies suggest that damage or depletion of stem/progenitor cells in the developing lung likely contributes to the pathogenesis of both BPD and COPD (including emphysema), thus highlighting the potential of stem/progenitor cell supplementation for the prevention or repair of lung injury. The use of stem/progenitor cells is being increasingly examined in experimental animal models and provides compelling evidence for the beneficial effects of stem cell therapy approaches for a wide variety of lung diseases [45-47]. Given the perturbations of the resident lung stem/progenitor cells in both BPD and COPD, the ideal therapeutic approach involves replenishing the damaged lung with healthy multipotent stem/progenitor cells that could repopulate, repair, and regenerate the injured lung. Indeed, several recent studies have demonstrated promising 
outcomes using different types of stem/progenitor cell types in animal models of BPD (Table 1) and COPD (Table 2).

6.1. Lung Progenitor/Stem Cells in Health and Disease. Observations from our lab in an oxygen-challenged neonatal rat model of BPD have shown significantly reduced numbers of circulating and resident mesenchymal stem cells (MSCs) in the lung [48]. It has also been shown that the umbilical cord blood (UCB) of preterm infants yields a higher amount of endothelial colony-forming cells (ECFCs; a specific subset of endothelial progenitor cells, EPCs) than that of termborn infants; however, those preterm ECFCs exhibited an increased susceptibility to in vitro oxygen exposure [49]. Of particular interest is the reduced number of ECFCs in preterm infants who subsequently developed BPD compared to nonBPD preterm infants [50].

Similarly, resident lung stem/progenitor cells in the presence of COPD exhibit comparable perturbed characteristics. A recent study by Liu and Xie [51] found that the number of early outgrowth EPCs (a subset of EPCs that exhibit a spindlelike morphology in-vitro culture at 4-7 days and express the hematopoietic lineage cell markers CD34, CD133, and VEGFR-2) [52] isolated from patients with COPD was significantly less than that of control subjects. Furthermore, the EPCs of COPD patients exhibited reduced cluster-forming numbers and impaired cell migratory capacity, suggesting that the capacity of EPCs to repair dysfunctional endothelium is compromised in COPD [51]. These dysfunctional characteristics of COPD EPCs were also confirmed in a study by Kim and colleagues [53], where they observed significantly lower colony-forming units and lower migratory capacity of circulating EPCs isolated from patients with emphysema. These findings from BPD and COPD studies highlight the potential of stem/progenitor cell supplementation for repair/regeneration of the lung.

6.2. Therapeutic Potential of Mesenchymal Stem Cells in BPD and COPD. Of the many different types of stem/progenitor cell therapies that have been used in experimental models, MSCs appear to be the most extensively examined cell type. MSCs possess the ability to differentiate and form various mesenchymal cell types, including bone, cartilage, and adipose cells, and can be sourced from the bone marrow, UCB, umbilical cord Wharton's jelly, the placenta, and adipose tissue.

6.2.1. MSCs in Preclinical Studies for BPD. Administration of bone marrow-derived MSCs, either intratracheally, intravenously, or intraperitoneally, has ameliorated numerous aspects of neonatal lung injury, as evident by mitigation of lung inflammation, prevention of lung vascular damage and alveolar growth arrest, inhibition of lung fibrosis, and improvement in exercise tolerance [48, 54-58].

Low engraftment and differentiation of these MSCs into the injured neonatal lung suggest that the potential mechanisms through which MSCs exert their actions are paracrine mediated. These speculations are supported by in vitro and in vivo studies demonstrating that administration of conditioned media (CdM) from MSCs has the ability to protect alveolar epithelial and lung microvascular endothelial cells from oxidative stress, prevent oxygen-induced alveolar growth arrest, and stimulate a subset of stem/progenitor cells, known as bronchoalveolar stem cells (BASCs), to aid in lung repair $[48,54,55,57,58]$. Furthermore, the therapeutic benefits of MSC-CdM may surpass those of MSCs, with invivo findings indicating a more profound therapeutic effect of MSC-CdM in preventing/repairing lung injury than that of MSCs [54].

Compared to the various available MSC sources, UCB represents a very appealing source of MSCs for therapeutic use in the newborn due to its clinically relevant, easily accessible, ethically viable, and readily available source of stem/progenitor cells. Chang and colleagues [59, 60] demonstrated that MSCs obtained from human UCB prevent hyperoxia-induced alveolar growth arrest and alleviate fibrotic changes in the neonatal rat lung. Interestingly, Chang et al. also show that the route of administration may alter the outcome, with intratracheal transplantation resulting in a more prominent attenuation of hyperoxiainduced lung injury than intraperitoneal transplantation [60]. Furthermore, Chang et al. recently demonstrated the dose-dependent effects of human UCB-derived MSCs in the oxygen-challenged neonatal rat lung [59]. This study indicated that intratracheal delivery of a minimum of $5 \times$ $10^{4}$ cells is required to exhibit efficient antiinflammatory, antifibrotic, and antioxidative effects following hyperoxiainduced lung injury in neonatal rats [59]. In light of these findings, further studies determining the optimal dose of MSCs for potential clinical benefit in human neonates are anticipated. More recently, data from our own lab has demonstrated the beneficial long-term effects of UCB-derived MSCs in an oxygen-challenged rat model of BPD [58]. Long-term assessment of 6-month-old rats showed no adverse effects of either MSC or MSC-CdM therapy and also demonstrated persistent improvements in adult exercise capacity and lung structure [58].

6.2.2. MSCs in Preclinical Studies for COPD. Repair of lung injury in experimental models of COPD/emphysema has also been demonstrated by many studies utilizing MSCs, derived from bone marrow, adipose tissue, and umbilical cord Wharton's jelly [61-70]. Huh and colleagues [61] used a cigarette smoke-induced experimental model of COPD/emphysema and showed that bone marrow-derived MSCs and their $\mathrm{CdM}$ were capable of restoring the alveolar structure and increased pulmonary vascularity. Zhen and colleagues [62] also used bone marrow-derived MSCs, but in a papaininduced model of COPD/emphysema, and showed alveolar structure improvements. The beneficial effects of MSCs have also been demonstrated in an elastase-induced experimental model of COPD/emphysema, where Katsha and colleagues [65] also showed preservation of the alveolar structure, reduced inflammation, and upregulation of growth factors. The bleomycin-induced adult lung injury model has also been implemented in many studies that demonstrate the beneficial effects of MSCs, as evident by reduced lung fibrosis and 
modulation of pulmonary inflammation [66-70]. Similar to the use of MSCs in experimental BPD animal models, the proposed mechanism of action is through a paracrine and immunomodulatory effect rather than cell engraftment [71].

Apart from MSCs, other reparative cells of interest include EPCs, amnion epithelial cells (AECs), and perivascular cells (PCs). The therapeutic potential of EPCs in neonatal lung injury has been effectively demonstrated in an oxygeninduced BPD mouse model [72]. Treatment of neonatal mice exposed to hyperoxia with intravenously administered bone marrow-derived angiogenic cells (a population of bone marrow myeloid-like precursor cells) showed restoration of the alveolar structure and vessel density to that of control (room air-exposed) levels [72]. Recently, the therapeutic potential of human AECs has been investigated in a sheep model of neonatal lung injury, induced by LPS administration in fetal sheep [73]. Since human AECs are sourced from placentae, which are normally discarded after birth, they present an easily accessible and ethically viable cell therapy candidate. Administration of AECs to fetal sheep exposed to LPS attenuated inflammation-induced changes in lung function and structure and reduced pulmonary inflammation [73]. Of particular interest is the ability of AECs to significantly increase the expression levels of SP$A$ and -C. The potential therapeutic effects of human AECs have also been examined in bleomycin-induced adult lung injury models $[74,75]$. Administration of AECs to adult mice exposed to bleomycin attenuated lung fibrosis, reduced collagen content, and decreased pulmonary inflammation $[74,75]$; partial restoration of lung function was also observed following AEC administration [75]. Recently, umbilical cordderived PCs have been shown to exhibit similar reparative potential to UCB-derived MSCs in a rat model of neonatal lung injury [58]. Umbilical cord-derived PCs, as a whole cell therapy or growth factor producers (i.e., CdM), rescued oxygen-induced arrested alveolar growth and improved longterm lung function [58]. The low engraftment into the lungs indicates that these cells act via immune modulation, rather than cell engraftment and differentiation. More detailed assessment of the therapeutic potential of these cells in other models of neonatal and adult lung injury will be of interest.

\section{Summary}

The long-term pulmonary outcomes reported in ex-preterm BPD children, adolescents, and adults highlight the potential link between altered early-life development and environment and chronic lung disease in adulthood. Findings from several exciting studies indicate that a variety of stem/progenitor cells can prevent and/or regenerate neonatal and adult lung injury in various experimental models. In terms of neonatal lung injury, additional studies in different animal models of BPD are necessary to broaden the current knowledge and understanding of the therapeutic potential of stem/progenitor cells. In doing so, further evidence for creating a strong rationale for translating this potential breakthrough into the clinic can be generated. Furthermore, by preventing or repairing neonatal lung injury in prematurely born infants, it is possible that the overall risk of COPD/emphysema development in later life may be reduced in this subset of the population.

\section{References}

[1] R. Harding and G. Maritz, "Maternal and fetal origins of lung disease in adulthood," Seminars in Fetal \& Neonatal Medicine, vol. 17, pp. 67-72, 2012.

[2] P. M. Wong, A. N. Lees, J. Louw et al., "Emphysema in young adult survivors of moderate-to-severe bronchopulmonary dysplasia," European Respiratory Journal, vol. 32, no. 2, pp. 321-328, 2008.

[3] J. R. Bourbon, O. Boucherat, J. Boczkowski, B. Crestani, and C. Delacourt, "Bronchopulmonary dysplasia and emphysema: in search of common therapeutic targets," Trends in Molecular Medicine, vol. 15, no. 4, pp. 169-179, 2009.

[4] D. Warburton, D. Tefft, A. Mailleux et al., "Do lung remodeling, repair, and regeneration recapitulate respiratory ontogeny?" American Journal of Respiratory and Critical Care Medicine, vol. 164, no. 10, pp. S59-S62, 2001.

[5] L. A. Joss-Moore, K. H. Albertine, and R. H. Lane, "Epigenetics and the developmental origins of lung disease," Molecular Genetics and Metabolism, vol. 104, pp. 61-66, 2011.

[6] J. P. Kinsella, A. Greenough, and S. H. Abman, "Bronchopulmonary dysplasia," Lancet, vol. 367, no. 9520, pp. 1421-1431, 2006.

[7] S. M. Schulzke and J. J. Pillow, "The management of evolving bronchopulmonary dysplasia," Paediatric Respiratory Reviews, vol. 11, no. 3, pp. 143-148, 2010.

[8] D. J. Henderson-Smart, J. L. Hutchinson, D. A. Donoghue, N. J. Evans, J. M. Simpson, and I. Wright, "Prenatal predictors of chronic lung disease in very preterm infants," Archives of Disease in Childhood: Fetal and Neonatal Edition, vol. 91, no. 1, pp. F40-F45, 2006.

[9] E. Ralser, W. Mueller, C. Haberland et al., "Rehospitalization in the first 2 years of life in children born preterm," Acta Paediatrica, vol. 101, no. 1, pp. e1-e5, 2012.

[10] L. Friedrich, P. M. C. Pitrez, R. T. Stein, M. Goldani, R. Tepper, and M. H. Jones, "Growth rate of lung function in healthy preterm infants," American Journal of Respiratory and Critical Care Medicine, vol. 176, no. 12, pp. 1269-1273, 2007.

[11] O. Hjalmarson and K. Sandberg, "Abnormal lung function in healthy preterm infants," American Journal of Respiratory and Critical Care Medicine, vol. 165, no. 1, pp. 83-87, 2002.

[12] L. Friedrich, R. T. Stein, P. M. C. Pitrez, A. L. Corso, and M. H. Jones, "Reduced lung function in healthy preterm infants in the first months of life," American Journal of Respiratory and Critical Care Medicine, vol. 173, no. 4, pp. 442-447, 2006.

[13] S. J. Gross, D. M. Iannuzzi, D. A. Kveselis, and R. D. Anbar, "Effect of preterm birth on pulmonary function at school age: A prospective controlled study," Journal of Pediatrics, vol. 133, no. 2, pp. 188-192, 1998.

[14] B. Robin, Y. J. Kim, J. Huth et al., "Pulmonary Function in Bronchopulmonary Dysplasia," Pediatric Pulmonology, vol. 37, no. 3, pp. 236-242, 2004.

[15] R. S. Tepper, W. J. Morgan, K. Cota, and L. M. Taussig, "Expiratory flow limitation in infants with bronchopulmonary dysplasia," Journal of Pediatrics, vol. 109, no. 6, pp. 1040-1046, 1986.

[16] J. E. Balinotti, V. C. Chakr, C. Tiller et al., "Growth of lung parenchyma in infants and toddlers with chronic lung disease 
of infancy," American Journal of Respiratory and Critical Care Medicine, vol. 181, no. 10, pp. 1093-1097, 2010.

[17] I. Narang, "Review series: what goes around, comes around: childhood influences on later lung health? Long-term follow-up of infants with lung disease of prematurity," Chronic Respiratory Disease, vol. 7, pp. 259-269, 2010.

[18] J. Fawke, S. Lum, J. Kirkby et al., "Lung function and respiratory symptoms at 11 years in children born extremely preterm: The EPICure study," American Journal of Respiratory and Critical Care Medicine, vol. 182, no. 2, pp. 237-245, 2010.

[19] L. W. Doyle, "Respiratory function at age 8-9 years in extremely low birthweight/very preterm children born in Victoria in 19911992," Pediatric Pulmonology, vol. 41, no. 6, pp. 570-576, 2006.

[20] E. B. Broström, P. Thunqvist, G. Adenfelt, E. Borling, and M. Katz-Salamon, "Obstructive lung disease in children with mild to severe BPD," Respiratory Medicine, vol. 104, no. 3, pp. 362-370, 2010.

[21] L. J. Smith, P. P. Van Asperen, K. O. McKay, H. Selvadurai, and D. A. Fitzgerald, "Reduced exercise capacity in children born very preterm," Pediatrics, vol. 122, no. 2, pp. e287-e293, 2008.

[22] L. Welsh, J. Kirkby, S. Lum et al., "The EPICure study: maximal exercise and physical activity in school children born extremely preterm," Thorax, vol. 65, no. 2, pp. 165-171, 2010.

[23] P. Santuz, E. Baraldi, P. Zaramella, M. Filippone, and F. Zacchello, "Factors limiting exercise performance in long-term survivors of bronchopulmonary dysplasia," American Journal of Respiratory and Critical Care Medicine, vol. 152, no. 4, pp. 1284-1289, 1995.

[24] C. E. Bolton, J. Stocks, E. Hennessy et al., "The EPICure Study: Association between hemodynamics and lung function at 11 years after extremely preterm birth," Journal of Pediatrics, vol. 161, no. 4, pp. 595-601, 2012.

[25] H. Clemm, O. Roksund, E. Thorsen, G. E. Eide, T. Markestad, and T. Halvorsen, "Aerobic capacity and exercise performance in young people born extremely preterm," Pediatrics, vol. 129, pp. e97-e105, 2012.

[26] D. F. Hacking, A. M. Gibson, C. Robertson, and L. W. Doyle, "Respiratory function at age 8-9 after extremely low birthweight or preterm birth in Victoria in 1997," Pediatric Pulmonology. In press.

[27] E. Kaplan, E. B. Yishay, D. Prais et al., "Encouraging pulmonary outcome for surviving, neurologically intact extremely premature infants in the post surfactant era," Chest, vol. 142, no. 3, pp. 725-733, 2012.

[28] P. Korhonen, J. Laitinen, E. Hyödynmaa, and O. Tammela, "Respiratory outcome in school-aged, very-low-birth-weight children in the surfactant era," Acta Paediatrica, vol. 93, no. 3, pp. 316-321, 2004.

[29] S. J. Kotecha, W. J. Watkins, S. Paranjothy, F. D. Dunstan, A. J. Henderson, and S. Kotecha, "Effect of late preterm birth on longitudinal lung spirometry in school age children and adolescents," Thorax, vol. 67, pp. 54-61, 2012.

[30] K. Kulasekaran, P. H. Gray, and B. Masters, "Chronic lung disease of prematurity and respiratory outcome at eight years of age," Journal of Paediatrics and Child Health, vol. 43, no. 1-2, pp. 44-48, 2007.

[31] X. M. Mai, P. O. Gäddlin, L. Nilsson et al., "Asthma, lung function and allergy in 12-year-old children with very low birth weight: a prospective study," Pediatric Allergy and Immunology, vol. 14, no. 3, pp. 184-192, 2003.
[32] T. Halvorsen, B. T. Skadberg, G. E. Eide, O. D. Røksund, K. H. Carlsen, and P. Bakke, "Pulmonary outcome in adolescents of extreme preterm birth: a regional cohort study," Acta Paediatrica, International Journal of Paediatrics, vol. 93, no. 10, pp. 1294-1300, 2004.

[33] L. W. Doyle, B. Faber, C. Callanan, N. Freezer, G. W. Ford, and N. M. Davis, "Bronchopulmonary dysplasia in very low birth weight subjects and lung function in late adolescence," Pediatrics, vol. 118, no. 1, pp. 108-113, 2006.

[34] I. Narang, M. Rosenthal, D. Cremonesini, M. Silverman, and A. Bush, "Longitudinal evaluation of airway function 21 years after preterm birth," American Journal of Respiratory and Critical Care Medicine, vol. 178, no. 1, pp. 74-80, 2008.

[35] E. J. L. E. Vrijlandt, J. Gerritsen, H. M. Boezen, R. G. Grevink, and E. J. Duiverman, "Lung function and exercise capacity in young adults born prematurely," American Journal of Respiratory and Critical Care Medicine, vol. 173, no. 8, pp. 890-896, 2006.

[36] M. Filippone, G. Bonetto, M. Corradi, A. C. Frigo, and E. Baraldi, "Evidence of unexpected oxidative stress in airways of adolescents born very preterm," European Respiratory Journal, vol. 40, no. 5, pp. 1253-1259, 2012.

[37] S. M. Aukland, K. Rosendahl, C. M. Owens, K. R. Fosse, G. E. Eide, and Halvorsen, "Neonatal bronchopulmonary dysplasia predicts abnormal pulmonary HRCT scans in long-term survivors of extreme preterm birth," Thorax, vol. 64, no. 5, pp. 405-410, 2009.

[38] G. Sharma and J. Goodwin, "Effect of aging on respiratory system physiology and immunology.," Clinical interventions in aging, vol. 1, no. 3, pp. 253-260, 2006.

[39] L. Wang, F. H. Y. Green, S. M. Smiley-Jewell, and K. E. Pinkerton, "Susceptibility of the aging lung to environmental injury," Seminars in Respiratory and Critical Care Medicine, vol. 31, no. 5, pp. 539-553, 2010.

[40] K. E. Pinkerton and F. H. Y. Green, "Normal Aging of the Lung," in The Lung: Development, Aging and the Environment, R. Harding, K. E. Pinkerton, and C. G. Plopper, Eds., pp. 213-233, Elsevier, London, UK, 2004.

[41] K. C. Meyer, "Aging," Proceedings of the American Thoracic Society, vol. 2, pp. 433-439, 2005.

[42] K. C. Meyer, W. Ershler, N. S. Rosenthal, X. G. Lu, and K. Peterson, "Immune dysregulation in the aging human lung," American Journal of Respiratory and Critical Care Medicine, vol. 153, no. 3, pp. 1072-1079, 1996.

[43] M. Filippone and E. Baraldi, "On early life risk factors for COPD," American Journal of Respiratory and Critical Care Medicine, vol. 183, no. 3, pp. 415-416, 2011.

[44] A. H. Jobe, "The new bronchopulmonary dysplasia," Current Opinion in Pediatrics, vol. 23, no. 2, pp. 167-172, 2011.

[45] C. Agostini, "Stem cell therapy for chronic lung diseases: hope and reality," Respiratory Medicine, vol. 104, no. 1, pp. S86-S91, 2010.

[46] C. J. Blaisdell, D. B. Gail, and E. G. Nabel, "National heart, lung, and blood institute perspective: lung progenitor and stem cells-gaps in knowledge and future opportunities," Stem Cells, vol. 27, no. 9, pp. 2263-2270, 2009.

[47] V. Sueblinvong and D. J. Weiss, "Stem cells and cell therapy approaches in lung biology and diseases," Translational Research, vol. 156, no. 3, pp. 188-205, 2010.

[48] T. Van Haaften, R. Byrne, S. Bonnet et al., "Airway delivery of mesenchymal stem cells prevents arrested alveolar growth in 
neonatal lung injury in rats," American Journal of Respiratory and Critical Care Medicine, vol. 180, no. 11, pp. 1131-1142, 2009.

[49] C. D. Baker, S. L. Ryan, D. A. Ingram, G. J. Seedorf, S. H. Abman, and V. Balasubramaniam, "Endothelial colony-forming cells from preterm infants are increased and more susceptible to hyperoxia," American Journal of Respiratory and Critical Care Medicine, vol. 180, no. 5, pp. 454-461, 2009.

[50] A. Borghesi, M. Massa, R. Campanelli et al., "Circulating endothelial progenitor cells in preterm infants with bronchopulmonary dysplasia," American Journal of Respiratory and Critical Care Medicine, vol. 180, no. 6, pp. 540-546, 2009.

[51] X. Liu and C. Xie, "Human endothelial progenitor cells isolated from COPD patients are dysfunctional," Molecular and Cellular Biochemistry, vol. 363, pp. 53-63, 2012.

[52] F. Timmermans, J. Plum, M. C. Yöder, D. A. Ingram, B. Vandekerckhove, and J. Case, "Endothelial progenitor cells: identity defined?" Journal of Cellular and Molecular Medicine, vol. 13, no. 1, pp. 87-102, 2009.

[53] E. K. Kim, J. H. Lee, H. C. Jeong et al., "Impaired colonyforming capacity of circulating endothelial progenitor cells in patients with emphysema," The Tohoku Journal of Experimental Medicine, vol. 227, pp. 321-331, 2012.

[54] M. Aslam, R. Baveja, O. D. Liang et al., "Bone marrow stromal cells attenuate lung injury in a murine model of neonatal chronic lung disease," American Journal of Respiratory and Critical Care Medicine, vol. 180, no. 11, pp. 1122-1130, 2009.

[55] K. A. Tropea, E. Leder, M. Aslam et al., "Bronchioalveolar stem cells increase after mesenchymal stromal cell treatment in a mouse model of bronchopulmonary dysplasia," American Journal of Physiology, vol. 302, pp. L829-L837, 2012.

[56] X. Zhang, H. Wang, Y. Shi et al., "The role of bone marrowderived mesenchymal stem cells in the prevention of hyperoxiainduced lung injury in newborn mice," Cell Biology International, vol. 36, pp. 589-594, 2012.

[57] G. Hansmann, A. Fernandez-Gonzalez, M. Aslam et al., "Mesenchymal stem cell-mediated reversal of bronchopulmonary dysplasia and associated pulmonary hypertension," Pulmonary Circulation, vol. 2, pp. 170-181, 2012.

[58] M. Pierro, L. Ionescu, T. Montemurro et al., "Short-term, longterm and paracrine effect of human umbilical cord-derived stem cells in lung injury prevention and repair in experimental bronchopulmonary dysplasia," Thorax. In press.

[59] Y. S. Chang, S. J. Choi, D. K. Sung et al., "Intratracheal transplantation of human umbilical cord blood derived mesenchymal stem cells dose-dependently attenuates hyperoxiainduced lung injury in neonatal rats," Cell Transplantation, vol. 20, pp. 1843-1854, 2011.

[60] Y. S. Chang, W. Oh, S. J. Choi et al., "Human umbilical cord blood-derived mesenchymal stem cells attenuate hyperoxiainduced lung injury in neonatal rats," Cell Transplantation, vol. 18, no. 8, pp. 869-886, 2009.

[61] J. W. Huh, S. Y. Kim, J. H. Lee et al., "Bone marrow cells repair cigarette smoke-induced emphysema in rats," American Journal of Physiology, vol. 301, pp. L255-L266, 2011.

[62] G. Zhen, H. Liu, N. Gu, H. Zhang, Y. Xu, and Z. Zhang, "Mesenchymal stem cells transplantation protects against rat pulmonary emphysema," Frontiers in Bioscience, vol. 13, no. 9, pp. 3415-3422, 2008.

[63] N. Shigemura, M. Okumura, S. Mizuno et al., "Lung tissue engineering technique with adipose stromal cells improves surgical outcome for pulmonary emphysema," American Journal of Respiratory and Critical Care Medicine, vol. 174, no. 11, pp. 1199-1205, 2006.

[64] N. Shigemura, M. Okumura, S. Mizuno, Y. Imanishi, T. Nakamura, and Y. Sawa, "Autologous transplantation of adipose tissue-derived stromal cells ameliorates pulmonary emphysema," American Journal of Transplantation, vol. 6, no. 11, pp. 2592-2600, 2006.

[65] A. M. Katsha, S. Ohkouchi, H. Xin et al., "Paracrine factors of multipotent stromal cells ameliorate lung injury in an elastaseinduced emphysema model," Molecular Therapy, vol. 19, no. 1, pp. 196-203, 2011.

[66] M. Kumamoto, T. Nishiwaki, N. Matsuo, H. Kimura, and K. Matsushima, "Minimally cultured bone marrow mesenchymal stem cells ameliorate fibrotic lung injury," European Respiratory Journal, vol. 34, no. 3, pp. 740-748, 2009.

[67] Y. Moodley, D. Atienza, U. Manuelpillai et al., "Human umbilical cord mesenchymal stem cells reduce fibrosis of bleomycininduced lung injury," American Journal of Pathology, vol. 175, no. 1, pp. 303-313, 2009.

[68] L. A. Ortiz, M. DuTreil, C. Fattman et al., "Interleukin 1 receptor antagonist mediates the antiinflammatory and antifibrotic effect of mesenchymal stem cells during lung injury," Proceedings of the National Academy of Sciences of the United States of America, vol. 104, no. 26, pp. 11002-11007, 2007.

[69] L. A. Ortiz, F. Gambelli, C. McBride et al., "Mesenchymal stem cell engraftment in lung is enhanced in response to bleomycin exposure and ameliorates its fibrotic effects," Proceedings of the National Academy of Sciences of the United States of America, vol. 100, no. 14, pp. 8407-8411, 2003.

[70] M. Rojas, J. Xu, C. R. Woods et al., "Bone marrow-derived mesenchymal stem cells in repair of the injured lung," American Journal of Respiratory Cell and Molecular Biology, vol. 33, no. 2, pp. 145-152, 2005.

[71] J. W. Lee, X. Fang, A. Krasnodembskaya, J. P. Howard, and M. A. Matthay, "Concise review: mesenchymal stem cells for acute lung injury: role of paracrine soluble factors," Stem Cells, vol. 29, no. 6, pp. 913-919, 2011.

[72] V. Balasubramaniam, S. L. Ryan, G. J. Seedorf et al., "Bone marrow-derived angiogenic cells restore lung alveolar and vascular structure after neonatal hyperoxia in infant mice," American Journal of Physiology, vol. 298, no. 3, pp. L315-L323, 2010.

[73] P. Vosdoganes, R. J. Hodges, R. Lim et al., "Human amnion epithelial cells as a treatment for inflammation-induced fetal lung injury in sheep," American Journal of Obstetrics and Gynecology, vol. 205, no. 2, pp. 156.e26-156.e33, 2011.

[74] Y. Moodley, S. Ilancheran, C. Samuel et al., "Human amnion epithelial cell transplantation abrogates lung fibrosis and augments repair," American Journal of Respiratory and Critical Care Medicine, vol. 182, no. 5, pp. 643-651, 2010.

[75] S. Murphy, R. Lim, H. Dickinson et al., "Human amnion epithelial cells prevent bleomycin-induced lung injury and preserve lung function," Cell Transplantation, vol. 20, pp. 909-923, 2011.

[76] A. E. Hegab, H. Kubo, N. Fujino et al., "Isolation and characterization of murine multipotent lung stem cells," Stem Cells and Development, vol. 19, no. 4, pp. 523-535, 2010.

[77] D. Wang, J. E. Morales, D. G. Calame, J. L. Alcorn, and R. A. Wetsel, "Transplantation of human embryonic stem cellderived alveolar epithelial type II cells abrogates acute lung injury in mice," Molecular Therapy, vol. 18, no. 3, pp. 625-634, 2010. 
[78] S. Aguilar, C. J. Scotton, K. McNulty et al., "Bone marrow stem cells expressing keratinocyte growth factor via an inducible lentivirus protects against bleomycin-induced pulmonary fibrosis," PLoS ONE, vol. 4, no. 11, article e8013, 2009. 


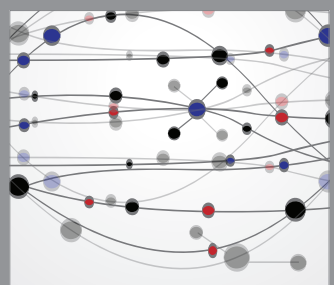

The Scientific World Journal
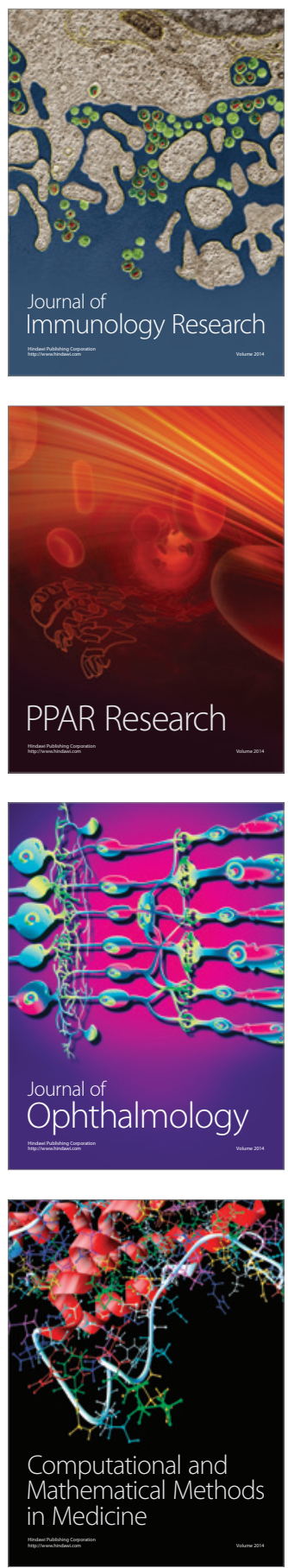

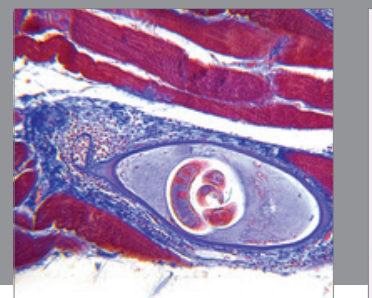

Gastroenterology

Research and Practice
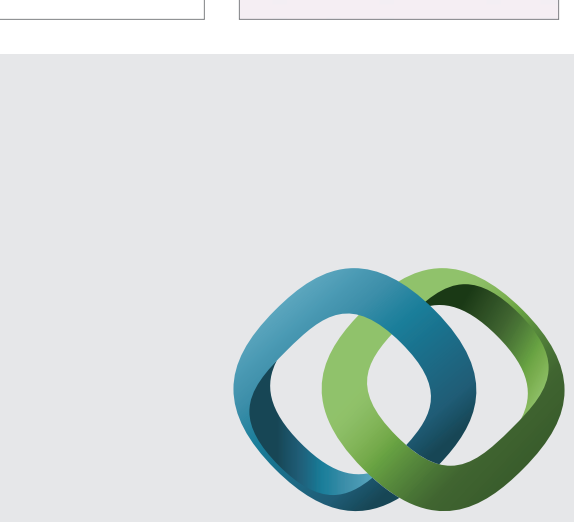

\section{Hindawi}

Submit your manuscripts at

http://www.hindawi.com
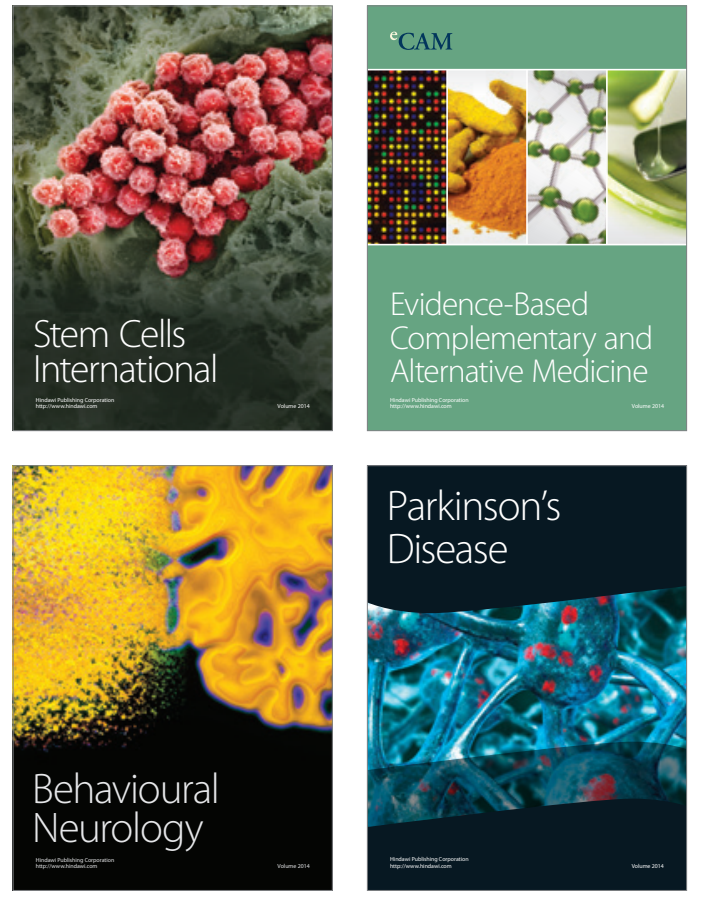
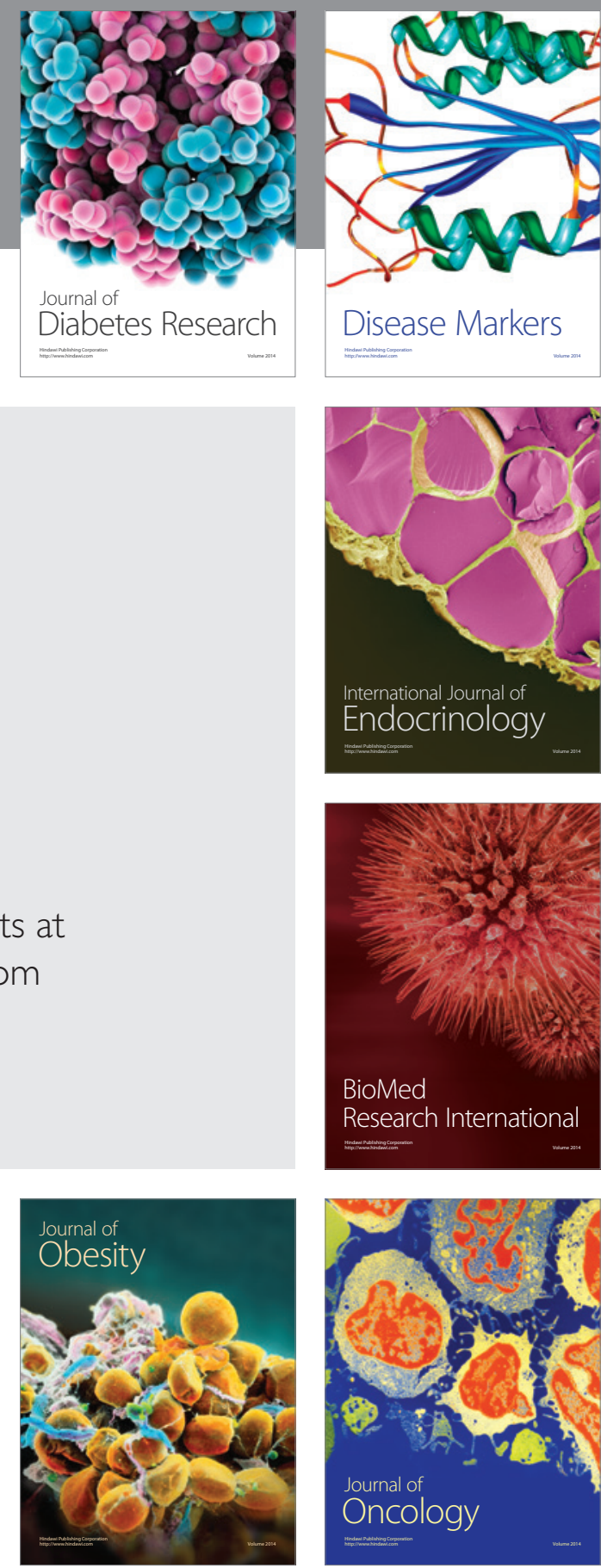

Disease Markers
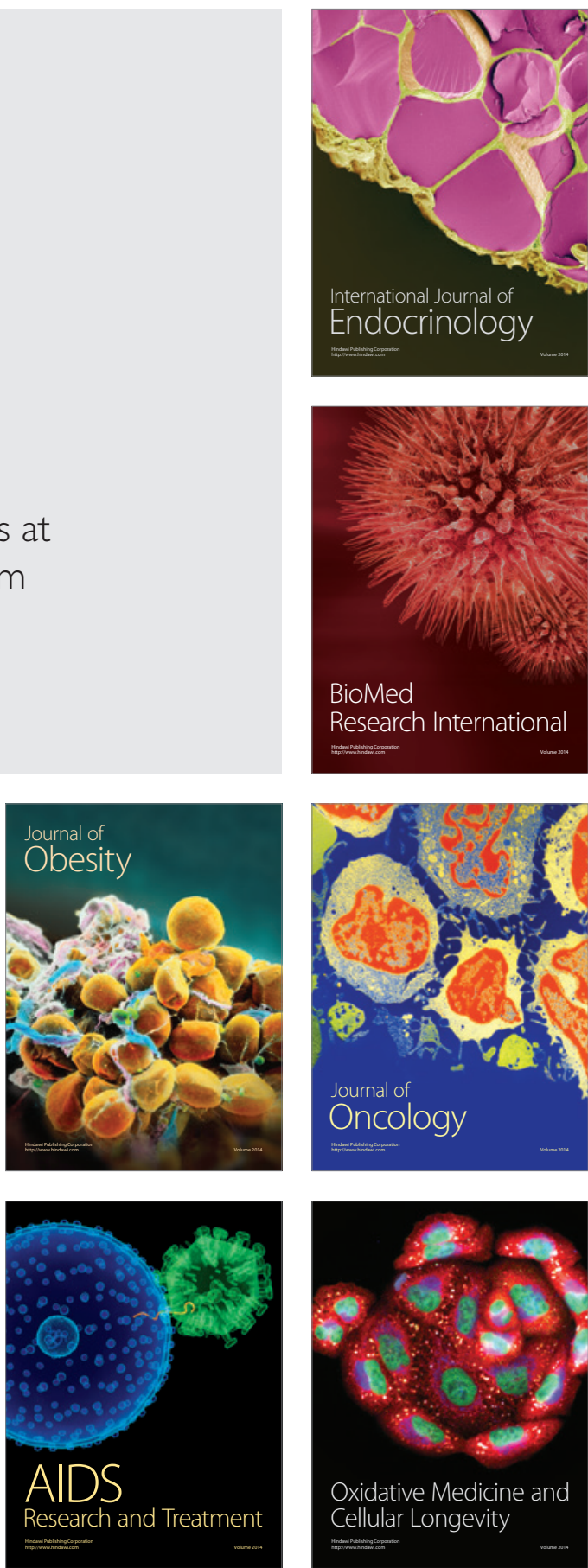